Published in final edited form as:

QJEcon. 2011 ; 126(1): 103-143.

\title{
Family Violence and Football: The Effect of Unexpected Emotional Cues on Violent Behavior
}

\author{
David Card and \\ Department of Economics, 549 Evans Hall \#3880, University of California, Berkeley, Berkeley, \\ CA94720, card@econ.berkeley.edu
}

Gordon B. Dahl

Department of Economics, University of California, San Diego, 9500 Gilman Drive \#0508, La Jolla, CA 92093, gdahl@ucsd.edu

\begin{abstract}
We study the link between family violence and the emotional cues associated with wins and losses by local professional football teams. We hypothesize that the risk of violence is affected by the 'gain-loss' utility of game outcomes around a rationally expected reference point. Our empirical analysis uses police reports of violent incidents on Sundays during the professional football season. Controlling for the pre-game point spread and the size of the local viewing audience, we find that upset losses (defeats when the home team was predicted to win by 4 or more points) lead to a 10 percent increase in the rate of at-home violence by men against their wives and girlfriends. In contrast, losses when the game was expected to be close have small and insignificant effects. Upset wins (when the home team was predicted to lose) also have little impact on violence, consistent with asymmetry in the gain-loss utility function. The rise in violence after an upset loss is concentrated in a narrow time window near the end of the game, and is larger for more important games. We find no evidence for reference point updating based on the halftime score.
\end{abstract}

\section{Introduction}

Violence by men against members of their own family is one of the most common yet perplexing forms of criminal behavior. ${ }^{1}$ One interpretation is that intra-family violence is instrumental behavior that is used by domineering men to control their partners and children (e.g., Dobash and Dobash, 1979). ${ }^{2}$ An alternative view is that family violence is expressive behavior that either provides positive utility to some men (e.g., Tauchen et al., 1991; Aizer, 2010), or arises unintentionally when an argument escalates out of control (e.g., Straus, Gelles, and Steinmetz, 1980; Johnson, 2009).

An expressive interpretation of family violence suggests a potentially important role for emotional cues (or "visceral factors") in precipitating violence. ${ }^{3}$ In this paper we study the

\footnotetext{
* This research was supported by a grant from the National Institute of Child Health and Human Development (1R01HD056206-01A1). We are grateful to the editor and four anonymous referees for many helpful comments and suggestions. Rachana Bhatt, Graton Gathright, and Yoonsoo Lee provided outstanding research assistance. We also thank Vincent Crawford, Julie Cullen, David Dahl, Botund Koszegi, Matthew Rabin and especially Stefano DellaVigna for valuable advice on an earlier draft, and seminar participants at Brigham Young University, Claremont McKenna, the Saint Louis Federal Reserve, SITE, UC Berkeley, UC Irvine, UC Santa Barbara, UC San Diego, and the University of Stavanger Norway for comments and suggestions.

${ }^{1}$ There are 2.5 to 4.5 million physical assaults inflicted on adult women by their intimate partner per year (Rand and Rennison, 2005). About one-third of female homicide victims in the U.S. were killed by their husband or partner (Fox and Zawitz, 2007).

${ }^{2}$ Chwe (1990) shows that painful punishment can arise in an agency model when the agent has low outside opportunities, even if punishment is costly for the principal. Bloch and Rao (2002) propose a model in which husbands use violence to signal the quality of their marriage to their wives' families.
} 
effects of the emotional cues associated with wins and losses by local professional football teams, using police reports of family violence during the regular season of the National Football League (NFL). Specifically, we hypothesize the risk of violence is affected by the 'gain-loss' utility associated with game outcomes around a rationally expected reference point (Koszegi and Rabin, 2006).

Our focus on professional football is motivated by three considerations. First, NFL fans are strongly attached to their local teams. Home games on Sunday afternoons typically attract $25 \%$ or more of the local television audience. ${ }^{4}$ Second, the existence of a well-organized betting market allows us to infer the expected outcome of each game, and use this as a reference point for gain-loss utility. ${ }^{5}$ Conditioning on the pre-game point spread also allows us to interpret any differential effect of a win versus a loss as a causal effect of the game outcome. Third, the structure of NFL competition and the availability of detailed game statistics make it easy to identify more or less salient games, and to measure the updated probability of a win by the home team midway through the game.

Two other recent studies have explored the link between football and violence. Gantz, Wang, and Bradley (2006) relate police reports of family violence to the occurrence of NFL games involving the local team, and find that game-days are associated with higher rates of violence. Rees and Schnepel (2009) document the effects of college football home games on rates of assault, vandalism, and alcohol-related offenses. ${ }^{6} \mathrm{We}$ go beyond these studies by examining the effects of wins and losses relative to pre-game expectations, by controlling for the size of the local viewing audience, by studying the inter-day timing of violent incidents, by comparing the effects of more and less salient games, and by testing for potential updating of the reference point for game outcomes using the score at half-time.

Our analysis incorporates family violence data for over 750 city and county police agencies in the National Incident Based Reporting System (NIBRS), merged with information on Sunday NFL games played by 6 teams over a 12-year period. Controlling for the pre-game point spread and the size of the local television viewing audience, we find that "upset losses" by the home team (losses when the team was predicted to win by 4 points or more) lead to a roughly $10 \%$ increase in the number of police reports of at-home male-on-female intimate partner violence. Consistent with reference point behavior, losses when the game was expected to be close have no significant effect on family violence. Upset wins (i.e., victories when the home team was expected to lose) also have no significant impact on the rate of violence, suggesting an important asymmetry in the reaction to unanticipated losses and gains.

The increases in violence after an upset loss are concentrated in a narrow time window around the end of the game, as might be expected if the violence is due to transitory emotional shocks. We also find that upset losses in more salient games (those involving a traditional rival, or when the team is still in playoff contention) have a bigger effect on the rate of violence. Finally, we test whether the reference point for emotional cues is revised during the first half of the game, but find no evidence of updating.

\footnotetext{
${ }^{3}$ See Loewenstein (2000) for a general discussion and Laibson (2001) and Bernheim and Rangel (2004) for models of the effect of external cues on decision-making.

${ }^{4}$ In 2008, NFL Sunday football games were the highest-rated local programs in $88 \%$ of the market-weeks. Nationally, the top 10 television programs for 18-49 year old men in 2008 were all NFL football games (NFL and Nielsen Media Research, cited in Ground Report, January 7, 2009).

5 As discussed in Levitt (2004) for example, football betting uses a point spread to clear the market. See Wolfers and Zitzewitz (2007) on the information-aggregating properties of betting markets.

${ }^{6}$ Rees and Schnepel (2009) show that games that involve the upset of a team ranked in the top 25 by the Associated Press (AP) poll have much higher rates of violence. Their definition of "upsets" is substantially different than ours, since a game can only be an upset if a nationally-ranked team is playing.
} 
Taken together our findings suggest that emotional cues based on the outcomes of professional football games exert a relatively strong effect on the occurrence of family violence. The estimated impact of an upset loss, for example, is about one-third as large as the jump in violence on a major holiday like the Fourth of July. More broadly, our research contributes to a growing body of work on the importance of reference point behavior, and provides field-based empirical support for Koszegi and Rabin's (2006) prediction that individuals frame gains and losses around a rationally-expected reference point, with stronger reactions to losses than gains.

\section{Modeling the Effect of Emotional Cues and Family Violence}

This section presents a simplified model of the impact of NFL game outcomes on the occurrence of family violence, and describes our empirical framework for measuring the effects of these cues. Our key hypothesis is that wins and losses generate emotional cues that reflect 'gain-loss' utility around a rational reference point. We consider two alternative mechanisms through which cues affect violence. The first builds on the family conflict paradigm in sociology (Straus, Gelles, and Steinmetz, 1980) and research on loss of control (e.g., Baumeister and Heatherton, 1996; Bernheim and Rangel, 2004; Loewenstein and O'Donoghue, 2007) and treats violence as an unintended outcome of interactions in conflictprone families. We assume that men are more likely to lose control when they have been exposed to a negative emotional shock. The second is a family bargaining model in which women endure violence in exchange for inter-family transfers, and men's demand for violence rises after a negative cue.

\section{II.A. Loss-of-Control Model}

Consider a couple that each period has some risk of a conflictual interaction (i.e., a heated disagreement or argument). With some probability $h \geq 0$ the interaction escalates to violence (i.e., the husband "loses control"). ${ }^{7}$ The likelihood of losing control is influenced by the emotional cues associated with the outcome $y$ of a professional football game, where $y=1$ indicates a home-team victory and $y=0$ indicates a loss. Letting $p=\mathrm{E}[y]$ we assume that:

$$
h=h^{0}-\mu(y-p), \quad(1)
$$

where $\mu$ is the gain-loss utility associated with the game outcome (Koszegi and Rabin, 2006). For simplicity we assume that $\mu$ is piece-wise linear, with

$$
\mu(y-p)=\alpha(y-p), y-p<0=\beta(y-p), y-p>0,
$$

for positive constants $\alpha$ and $\beta$. Loss aversion implies that $\alpha>\beta$, i.e., that the marginal effect of a positive cue is smaller than the marginal effect of a negative cue.

Recognizing that $y$ is binary, the implied probabilities of a loss of control are

$$
\begin{array}{ll}
h^{L}(p)=h^{0}+a p & \text { ify }=0 \text { (aloss) } \\
h^{W}(p)=h^{O}-\beta(1-p) & \text { ify=1(awin) }
\end{array} .
$$

The upper line in Figure 1 represents $h^{L}(p)$. When $p=0$ a home-team loss is fully anticipated and there is no emotional cue, so $h^{L}=h^{O}$. When $p>0$ a loss is "bad news", with a stronger negative cue the higher is $p$ : thus $h^{L}$ is increasing in $p$. The lower line in the figure

\footnotetext{
${ }^{7}$ Strictly speaking our model focuses on the risk of violent interactions between partners: the outcome could involve injuries to both partners. In our data about $80 \%$ of the victims of intimate partner violence are women, so we assume a male perpetrator.
} 
represents $h^{W}(p)$. A win when $p=0$ is the "best possible" news, leading to the lowest probability of loss of control, $h^{0}-\beta$. For higher values of $p$ a win is less of positive shock, so $h^{W}$ is also increasing in $p$.

Assuming that the probability of a conflictual interaction is $q \searrow 0$, the probability of a violent incident, conditional on watching the game, is $q h$. If the husband always watches, the probability of violence is therefore $\left(h^{0}+\alpha p\right) q$ in the event of a loss and $\left(h^{0}-\beta(1-p)\right) q$ in the event of a win. The differential effect of a loss versus a win on the probability of violence is:

$$
\Delta(\operatorname{risk} \mid p)=[\beta+(\alpha-\beta) p] q,
$$

which is positive and increasing in $p$, assuming that $\alpha>\beta$.

In Card and Dahl (2009) we present a forward-looking model in which husbands decide in advance whether to watch a game or not, taking into account the pleasure of watching a win versus a loss, and the risk of exposure to the emotional cue if they watch. In this case the differential effect of a loss versus a win on the probability of violence can be written as:

$$
\Delta(\operatorname{risk} \mid p)=[\beta+(\alpha-\beta) p] \times \mathrm{E}[q \mid \text { watch }, p] \times \operatorname{Prob}[\operatorname{watch} \mid p] .
$$

A comparison of (4) to (3) shows that discretionary viewing behavior will reinforce the effect of an increase in $p$ on the differential effect of a loss versus a win if more people watch a game when $p$ is higher, and/or if the composition of the viewing audience shifts toward more conflict-prone men when $p$ is higher.

\section{II.B. An Alternative Model}

A simple loss-of-control model is broadly consistent with the literature on situational family violence (e.g., Straus, Gelles, and Steinmetz, 1980; Gelles and Straus, 1988; Johnson, 1995), and with recent economic models of addiction (Bernheim and Rangel, 2004) and failure of self control (Loewenstein and O'Donoghue, 2007). In terms of predictions linking emotional cues to violence, however, it is indistinguishable from a family bargaining model in which men value the expression of violence and their preferences are affected by emotional cues from a gain-loss function like $\mu(y-p)$ in equation (1). ${ }^{8}$ A potentially important distinction between these models is in the victim's reaction to violence. In a bargaining model the victim is compensated for her injuries, and the optimal choice of violence equates the husband's willingness to pay for violence with his partner's marginal cost. Given that, victims have no incentive to call the police or take other protective action (and in fact outside intervention is inefficient, except for externalities imposed on third parties, such as children). ${ }^{9}$ Protective behavior is more easily interpreted in a loss-of-control model in which neither party benefits from violence. Nevertheless, both models imply a similar link between emotional cues and the probability of family violence.

\footnotetext{
${ }^{8}$ Tauchen et al. (1991), Farmer and Tiefenthaler (1997), Bowlus and Seitz (2006), and Aizer (2010) all assume that men value violence and their partners tolerate it in return for higher transfers. An efficient bargain with unrestricted transfers maximizes E[ U(y$\left.\left.c_{\mathrm{W}}, \mathrm{v}, \mathrm{h}\right)\right]$ subject to $\mathrm{E}\left[\mathrm{V}\left(\mathrm{c}_{\mathrm{W}}, \mathrm{v}\right)\right] \geq \mathrm{V}^{0}$, where $\mathrm{y}=$ family income, $\mathrm{c}_{\mathrm{W}}=$ consumption of wife, $\mathrm{v}=$ violence, $\mathrm{h}=\mathrm{cue}, \mathrm{U}$ is the male's utility and $\mathrm{V}$ is the female's. The optimal choices for $\mathrm{v}$ and $\mathrm{c}_{\mathrm{W}}$ equate the husband's marginal willingness to pay for violence with his partner's marginal supply price. Assuming that negative cues increase the willingness to pay for violence, the level of violence demanded by the husband (and supplied by the wife) will respond as in equation (3). Our reading of the extensive family violence literature outside of economics is that no one thinks a marginal condition like this is true - in other words, the cost of violence to the partner in the "high cue" condition is often far beyond the "price" that is paid by the perpetrator.

In the NIBRS data we analyze, we note it need not be the victim who reports IP violence to the police.
} 


\section{II.C. Evaluating the Effect of Emotional Cues}

We test for the predicted effects of positive and negative emotional cues using a Poisson count model for the number of police-reported episodes of family violence in cities and counties in states with a "home" NFL team. As discussed below we classify games based on the Las Vegas point spread into three categories: home team likely to win, opposing team likely to win, or game expected to be close. We then fit models that include a full set of interactions between the ex-ante classification and whether the game was a won or lost by the home team $(3 \times 2=6$ categories), treating non-game days (i.e., Sundays when the home team has a bye week or is playing on another day of the week) as the base case. As a robustness check, we also fit a model with a polynomial in the point spread, interacted with the game outcome.

Our key identifying assumption is that the outcome of an NFL game is random, conditional on the Las Vegas spread. Conditioning on the pre-game spread we can therefore interpret any difference between the rate of family violence following a win or loss as a causal effect of the outcome of the game. We test for reference point behavior by testing whether the impact of a loss is greater when the home team was expected to win than when the game was expected to be close, or the team was expected to lose. We also test for asymmetric reactions to good and bad news by comparing the magnitude of the effects of upset losses and upset wins.

\section{Data Sources and Sample Construction}

\section{III.A. Measuring Family Violence: NIBRS Data on Police-Reported Violence}

Our empirical analysis is based on police reports of family violence in the National IncidentBased Reporting System (NIBRS). NIBRS includes reports of crime to individual police agencies: the reports are not necessarily associated with an arrest. ${ }^{10}$ Each report includes information on the characteristics of the victim (age, gender, etc.), the offender (gender, relationship to the victim), and the incident (date, time of day, location, injuries).

NIBRS has two main advantages for our study. First, it includes all the family violence incidents recorded by a given agency. Since family violence is relatively rare, a complete count is needed to measure responses to NFL game outcomes on specific days in specific locations. Second, NIBRS includes real-time information on the date and time of day of the incident. Other sources of information on family violence (such as the National Crime Victimization Survey) are based on recall over a multiple-month period and cannot be used to measure occurrences by exact day and time.

One limitation of NIBRS is that it only includes police-reported family violence. ${ }^{11} \mathrm{~A}$ comparison of the implied rate of violence experienced by women age 18-54 in NIBRS to the rate in the 1995 National Violence Against Women Survey (NVAWS) suggests that NIBRS captures a relatively high fraction of serious violence (i.e., episodes that would be classified as assault or intimidation). Specifically, we estimate that the annual risk of IPV is approximately $1.6 \%$ per year in the 2000 NIBRS, versus $1.3 \%$ per year in the NVAWS (1995-96). ${ }^{12}$ A second limitation is that participation by police agencies in NIBRS is

\footnotetext{
${ }^{10}$ About half of family assaults in the NIBRS result in an arrest (Durose et al., 2005; Hirschel, 2008). Direct arrests by police officers with no intervening report of a crime are also included in NIBRS. Information on the NIBRS data set is available at the National Archive of Criminal Justice Data, http://www.icpsr.umich.edu/NACJD/NIBRS/.

${ }^{11}$ Only about one-half of adult women in the National Crime Victimization Survey who were assaulted by their spouse or partner reported the incident to police (Durose et al., 2005).

${ }^{12}$ To construct a national incidence rate from the NIBRS we assume that information on the family relationship of the perpetrator is missing at random, and inflated the incident rates for the agencies in NIBRS to the national level using relative populations as of 2000.
} 
voluntary, and is relatively low. The total fraction of the U.S. population covered by NIBRS was only $4 \%$ in 1995 , but had risen to $25 \%$ by 2006 .

As has been noted in other studies (e.g., Vazquez, Stohr and Purkiss, 2005; Gantz, Wang, and Bradley, 2006) the rate of family violence varies substantially across the days of the week, with much higher rates on weekends than weekdays. In view of these patterns, and the small number of NFL games on days other than Sunday, we have elected to simplify our analysis by limiting our sample to the 17 Sundays during the regular NFL season. We define intimate partner violence (IPV) as an incident of simple assault, aggravated assault, or intimidation by a spouse, partner, or boyfriend/girlfriend. Our primary focus is on male-onfemale IPV occurring at home between noon and midnight Eastern Time.

Table 1 provides summary statistics for IPV for our estimation sample (Sundays during the regular football season) for the set of NIBRS agencies used in our analysis (all reporting police agencies in the set of states that we match to NFL teams, as described in the next section). ${ }^{13}$ In our estimation sample, the overall rate of IPV is 1.28 per 100,000 individuals per day. ${ }^{14}$ Panel A shows how the rate of intimate partner violence varies by location and victim-offender relationship. Most of the victims of IPV are women (81\%), and most are victimized at home $(82 \%)$, leading to our focus on at-home male-on-female incidents. ${ }^{15}$ Within this class, violence by husbands against their wives and violence by men against unmarried partners account for roughly equal shares.

Panel B narrows the focus to male-on-female violence occurring at home. To crudely characterize the severity of an incident, we classified aggravated assaults and other incidents involving physical injury as "serious assaults," and the remaining forms of IPV as "minor assaults". ${ }^{16}$ Using this classification just over one-half of male-on-female at-home IPV incidents are serious assaults.

Alcohol use is widely believed to contribute to family violence (Klostermann and FalsSteward, 2006) and may amplify the effects of emotional cues (Exum, 2002). Unfortunately, alcohol use information in NIBRS is limited to a single variable indicating whether the offender was suspected of using alcohol (or drugs) during or shortly before the offense. Overall, about $20 \%$ of at-home male-on-female incidents of IPV list alcohol or drugs as a contributing factor.

\section{III.B. Matching NFL Team Data to NIBRS Violence Data}

We link the NIBRS data to the team records for "local" NFL franchises. Since NIBRS data are unavailable for many larger cities, relatively few NFL teams can be matched to crime rates in the city (or county) that hosts their home stadium. As an alternative, we focus on

\footnotetext{
${ }^{13}$ We include incidents reported by city and county agencies but exclude state police, college police, and special agencies. We limit the sample to agencies which report data on any crime (not just IPV) for at least 13 out of 17 Sundays in a season. Copies of the programs that we used to process the publicly available NIBRS data are available in the online appendix.

${ }^{14}$ We refer to the hours between noon and midnight ET as a day; these hours account for roughly $60 \%$ of at-home male-on-female IPV. Ideally the rate of intimate partner violence would be expressed relative to the number of intimate partner couples. In 2000 there were approximately 21 intimate partnerships per 100 people in the U.S. population: thus the rate per couple is approximately 4.8 times the rate per person. Our models include agency fixed effects and therefore control flexibly for most of the variation in the size of the at-risk population.

${ }^{15}$ The relative fraction of female victims of intimate partner violence is controversial because some data sources (in particular, behavioral checklists that collect incidents of slapping and pushing as well as more serious violence) find that men and women are equally likely to be victimized (e.g., Straus, Gelles, and Steinmetz, 1980). Police reports and victimization surveys suggest that women are more likely to be the victims of relatively serious violence (see Hamby, 2005, Table I).

16 NIBRS uses the FBI's definition of aggravated assault, which is an unlawful attack where the offender wields a weapon or the victim suffers obvious severe or aggravated injury. Simple assault is also an unlawful attack, but does not involve a weapon or obvious severe or aggravated bodily injury. Intimidation is the act of placing a person in reasonable fear of bodily harm without a weapon or physical attack.
} 
cities and counties in states where there is a single NFL team (or nearby team), assigning all jurisdictions within a state to that team. Using this approach, and requiring that at least 4 years of crime data are available for a given team, we were able to match six NFL teams to 763 NIBRS agencies.

Table 2 shows the six football teams in our sample, with the associated NIBRS states listed in parentheses. ${ }^{17}$ For each team we also show the win-loss record in the sample years for which NIBRS data are available, and the number of reporting agencies in the state in that year. Three teams (the Carolina Panthers, Detroit Lions, and New England Patriots) have NIBRS data available for all 12 years, starting in 1995 and continuing to 2006. The three remaining teams (the Denver Broncos, Kansas City Chiefs, and Tennessee Titans) enter the NIBRS sample in later years. Within a state the number of reporting agencies in NIBRS tends to rise over time, though there are some downward fluctuations as certain agencies leave the program.

The win-loss records reported in Table 2 display wide variation across teams. Detroit had a weak record over most of the sample period, while Denver and New England were relatively successful. Even for a given team, however, there are swings from year to year. Denver, for example, had a 14-2 win-loss record in the 1998 season (and won the Superbowl), but had a losing season in 1999. Since predicted game outcomes tend to be based on recent past performance, these patterns hint at the prevalence of both upset losses (e.g., during the Denver Bronco's 1999 season) and upset wins (e.g., during the Kansas City Chief's 2003 season). We characterize upset losses and upset wins more formally using the Las Vegas point spread in the next subsection.

In all, the 6 teams in our sample can be matched to 993 regular season football games and 53 playoff games. The characteristics of these games are shown in the upper panel of Table 3. The vast majority ( $87 \%$ ) of the regular season games were played on Sundays. As noted earlier, given the seasonal and intra-week variation in family violence rates, we elected to simplify our empirical design by focusing on regular-season Sunday games. The characteristics of these games and their associated local television market are summarized in panels B and C of Table 3 .

\section{III.C. Expected Outcomes from Betting Markets}

Betting on NFL game outcomes is organized through Las Vegas bookmakers, who equilibrate the market using a point spread. If the point spread is -3 for one team against another, the team must win by more than 3 points for a bet on that team to pay off. The market assessment of the outcome of a game is contained in the closing value of the point spread (the so-called "closing line").

Previous research has suggested that the point spread is an unbiased predictor of game outcomes in the NFL (e.g., Pankoff 1968; Gandar et al., 1988). To verify this conclusion, we collected data on point spreads and final scores for all 3,725 NFL football games played during the 1995-2006 seasons. Figure 2 shows the relationship between the actual and predicted point spread in each game. The actual spread is "noisier" than the predicted spread, but the two are highly correlated. In fact, a regression of the actual on the predicted spread yields a coefficient of 1.01 (standard error $=0.03$ ). Thus, there is no evidence against the null hypothesis of an efficient prediction. Moreover, the R-squared of the relationship is relatively strong $(0.20)$ suggesting that the closing line is an informative predictor of game outcomes.

\footnotetext{
${ }^{17}$ Kansas City is in Missouri, but we assume fans in Kansas also follow the team. NIBRS has no data for Missouri agencies until 2006, the last year of our sample period.
} 
The vertical lines in Figure 2 divide the predicted spreads into three regions, depending on whether the home team is predicted to win by at least 4 points, predicted to lose by at least 4 points, or predicted to have a close game. About $45 \%$ of games are expected to be close: the remaining games are equally divided in the two tails. In our empirical analysis we use these three categories to classify games as "predicted wins", "predicted close games", and "predicted losses" for the home team.

Our model is written in terms of the ex-ante probability of a home-team win, rather than the point spread. The mapping between the two is shown in Figure 3. To derive this relationship we regressed the probability of a victory by the home team on a third order polynomial in the spread. The fitted relationship follows the expected "inverse S-curve" shape, and is symmetric. For spreads of \pm 14 points (a range that includes $98 \%$ of games) the probability of a win is very close to linear, with each onepoint increase in the spread translating into a $3 \%$ decrease in the probability of a win. For games with a spread of -4 points or less ("predicted wins") the probability of a home team victory is $63 \%$ or greater. For "predicted losses" (spread $\geq 4$ ) the probability of a win is $37 \%$ or less.

Panel B of Table 3 summarizes the predicted outcomes of the 866 regular-season Sunday games in our IPV analysis sample. Of these games, $283(33 \%)$ were predicted wins for the home team, 206 (24\%) were predicted losses, and 377 (44\%) were predicted close games. The greater number of predicted wins than losses in our sample reflects the inclusion of two relatively successful teams (Denver and New England). We also report the actual outcomes of the games: the home team lost relatively few (28\%) of the games they were favored to win by 4 or more points, and won relatively few (32\%) of the games they were predicted to lose by 4 or more points. Among predicted close games the home team victory rate was approximately $50 \%$.

As discussed in Section V.D, below, we present some analyses of game outcomes relative to the actual point spread at halftime (which we call the "halftime spread" - note that this is not an updated predicted spread from betting markets, but rather the observed point difference at halftime). Like the final score, the halftime spread is more variable than the pre-game spread: by the midpoint of the game only $28 \%$ of games are closer than 4 points, while $44 \%$ are within the same range using the pre-game spread. The halftime spread is also a better predictor of the final game outcome. For example, among games where the home team led by 4 points or more at halftime, the fraction of losses was $18 \%$ (versus $28 \%$ using the same classification of the pre-game spread).

Panel B also shows two other important characteristics of NFL games that we explore in later analyses: the starting time, and the likely emotional salience of a game. The largest share of games (68\%) in our sample had a 1:00 PM starting time. Most of the others (26\%) had a 4:00 PM start time, while only 6\% were night games. We consider three measures of emotional salience: whether the home team was still in playoff contention; whether the game was played against a traditional "rival" team; and whether the game involved an unusually high number of sacks, turnovers, or penalty yards. ${ }^{18}$ Most regular season games (68\%) are played when the team is still in playoff contention, while about one-fifth are played against a traditional rival, and about $40 \%$ involve a high number of sacks, turnovers, or penalty yards. We define "highly salient" games as those in which the home team was still in playoff

\footnotetext{
${ }^{18}$ We classify a team as out of contention once the predicted probability of making the playoffs (based on the historical record for teams with a similar win-loss record at the same point in the season) is under $10 \%$. We identified traditional rivalries using information from "Rivalries in the National Football League" on Wikipedia. A list of the rival team pairs we use is available on request.
} 
contention and either played against a traditional rival or had an unusual number of sacks, turnovers, or penalty yards. These games represent $37 \%$ of our sample.

\section{III.D. Measures of Viewership}

We purchased data from Nielsen Media Research ("Nielsen") for the six television markets corresponding to the teams in our matched NIBRS-NFL sample. Nielsen uses information from metering devices installed in a sample of homes to estimate the fraction of all "television households" that are watching a given program at a given time. Panel C of Table 3 shows the Nielsen ratings for the regular season Sunday football games in our estimation sample (each Nielsen point represents 1 percent of local television households). On average, $24 \%$ of all households watch their local team play on a typical Sunday. In contrast, the Sunday afternoon television audience when the local team is not playing is only one-fourth as large.

Figure 4 plots the fraction of households watching a game (deviated from the average viewership in the same media market on Sunday game-days) against the pre-game spread. The estimated regression line in the graph shows that the expected audience falls by about 1 percentage point as the spread rises from -4 (a predicted win by the home team) to +4 (a predicted loss). This is not a large effect, and we infer that any differential reaction to the outcomes of predicted wins versus predicted losses is unlikely to be attributable to changes in viewership.

\section{Econometric Model and Main Estimation Results}

\section{IV.A. Econometric Model}

Given the incident-based nature of NIBRS data, we specify a Poisson regression model for the number of incidents of intimate partner violence reported by a given police agency on a given Sunday of the regular NFL season. Specifically we assume that

$$
\log \left(\mu_{j t}\right)=\theta_{j}+X_{j t} \gamma+\mathrm{f}\left(p_{j t}, y_{j t} ; \lambda\right)
$$

where $\mu_{j t}$ represents the expected number of incidents of IPV reported by agency $j$ in time period $t, \theta_{j}$ represents a fixed effect for the agency (which controls for the size and overall characteristics of the population served by the agency), $X_{j t}$ represents a set of time-varying controls (e.g., controls for season and weather), and $\mathrm{f}\left(p_{j t}, y_{j t} ; \lambda\right)$ is a general function of $p_{j t}$, the probability of a victory by the home team for a game played on date $t$, and $y_{j}$, the actual game outcome, with parameters $\lambda$. We assume that $p_{j t}=\mathrm{p}\left(S_{j t}\right)$ where $S_{j t}$ is the observed pregame point spread, allowing us to write

$$
\log \left(\mu_{j t}\right)=\theta_{j}+X_{j t} \gamma+g\left(S_{j t}, y_{j t} ; \lambda\right)
$$

Our primary interest is in the effect of a loss or win by the home team, controlling for the spread. Assuming that the Las Vegas betting market provides efficient forecasts of NFL game outcomes, the actual outcome of a game is "as good as random" when we control for the spread, and a specification like $\left(5^{\prime}\right)$ yields unbiased estimates of the causal effect of a loss relative to a win. ${ }^{19}$

An advantage of a Poisson specification is that fixed effects can be included without creating an incidental parameters problem (see Cameron and Trivedi, 1998). This is

\footnotetext{
${ }^{19}$ Formally, for a binary random variable $y$ with mean $p, \mathrm{E}[y \mid p, Z]=\mathrm{E}[y \mid p]$ for any $Z$, so conditioning on $p, y$ is independent of $Z$. Assuming the mapping $p(S)$ from the spread to $p$ is invertible and does not depend on $Z, \mathrm{E}[y \mid S, Z]=\mathrm{E}[y \mid p, Z]=\mathrm{E}[y \mid p]$, so $y$ is independent of $Z$ conditioning on $S$.
} 
potentially important in the NIBRS context because there are many small police agencies with relatively low counts of family violence incidents. A second useful property of a Poisson specification is that consistency of the maximum likelihood estimates of the parameters associated with the time-varying covariates (and in particular, the parameters $\lambda$ ) only requires that we have correctly specified the conditional mean for $\log \left(\mu_{j t}\right)($ Cameron and Trivedi, 1986). Consistency does not require that the arrival process for IPV incidents is actually Poisson.

\section{IV.B. Baseline Empirical Results}

Table 4 presents results for our baseline Poisson regressions for at-home male-on-female intimate partner violence occurring between the hours of $12 \mathrm{pm}$ and $12 \mathrm{am}$ on Sundays of the NFL regular season. In these models we assume that

$$
\begin{aligned}
g\left(S_{j t}, y_{j t}, \lambda\right) & =\lambda_{1} \cdot 1\left(S_{j t} \leq\right. \\
& -4)+\lambda_{2} \cdot 1\left(S_{j t} \leq\right. \\
& -4) 1\left(y_{j t}\right. \\
& =0)+\lambda_{3} \cdot 1\left(-4<S_{j t}<4\right)+\lambda_{4} \cdot 1\left(-4<S_{j t}<4\right) 1\left(y_{j t}\right. \\
& =0)+\lambda_{5} \cdot 1\left(S_{j t} \geq 4\right) \\
& +\lambda_{6} \cdot 1\left(S_{j t} \geq 4\right) 1\left(y_{j t}=1\right)
\end{aligned}
$$

i.e., we include dummies for three ranges of the spread, and interactions of these dummies with a game outcome indicator. The main coefficients of interest are $\lambda_{2}, \lambda_{4}$, and $\lambda_{6}$, which measure the effects of an upset loss, a close loss, and an upset win, respectively. The coefficients associated with the range of the spread $\left(\lambda_{1}, \lambda_{3}, \lambda_{5}\right)$ are also potentially interesting, but less easily interpreted, since variation in $S$ may be correlated with other factors that affect the likelihood of IPV.

The basic model in column (1) of Table 4 includes the spread indicators and the interactions with the win or loss variables, as well as a set of agency fixed effects. Columns 2-5 add in three sets of time-varying covariates: season, week of season, and holiday dummies; local weather conditions on the day of the game; and the Nielsen Rating for the local NFL game broadcast. The Nielsen data are only available for the $90 \%$ of the game days in our sample that occur in 1997 or later. To check the sensitivity of our results to the sample, column 4 presents a specification identical to the one in column 3 (with agency fixed effects and date and weather controls) but fit to the subsample with Nielsen data.

Focusing on the coefficients associated with the game outcome (in the first three rows of the table) notice that the estimates are quite stable across specifications, as would be anticipated if the game outcome is orthogonal to the other covariates, conditional on the spread. ${ }^{20}$ The estimates show that an upset loss leads to an approximately $10 \%$ increase in the rate of male-on-female at-home IPV. In contrast, the estimated effects of a loss when the game was predicted to be close are only about one-fourth to one-third as large in magnitude, and are never significant. The difference provides direct support for reference-point behavior of fans. Even more surprising, perhaps, is that upset wins appear to have little or no protective effect. Indeed, the estimated effects of an upset win are all positive, rather than negative as would be expected if the reaction to wins and losses is symmetric. Formal tests for

\footnotetext{
${ }^{20}$ Estimates of the complete set of coefficients for the baseline model in column 3 of Table 4 are presented in Appendix Table 5 of the online appendix.
} 
symmetry (comparing the effect of an upset loss to the negative of the effect for an upset win) are shown in the third-last row of the table and indicate substantial evidence of loss aversion. $^{21}$

In column 5 we explore the effect of controlling for the number of households tuned in to watch a local game. The Nielsen audience ratings are a significant factor in game day violence $(\mathrm{t}=2.2)$, with intimate partner violence rising by about $0.3 \%$ for each percentage point increase in the number of households watching the game. Importantly, however, the addition of this proxy for the number of couples at home together during a game has no effect on the estimated effects of the game outcomes. This suggests that the asymmetric reaction to upset losses and upset wins cannot be attributed to the lower number of viewers for expected losses.

\section{Extensions and Robustness Checks}

\section{V.A. Intra-day Timing of Violence Reports}

Our baseline specifications examine the effect of NFL game outcomes on incidents of IPV in the twelve hour period starting at noon. Using NIBRS information on the timing of incident reports (which is coded to the hour of the day) we can refine these models and check whether the pattern is consistent with a causal effect of the game outcome.

Specifically, we fit separate models for incidents in various 3 hour time windows, allowing separate coefficients for games starting at 1 PM (68\% of Sunday games) and 4 PM (26\% of Sunday games). ${ }^{22}$ The models - presented in Table 5 - include the Nielsen rating for the number of households watching a game, although the key coefficients are very similar when this variable is excluded.

Each column of Table 5 shows the effects of game outcomes on violence in a different time window. For the $12 \mathrm{PM}$ to $3 \mathrm{PM}$ window (column 1) there is no significant effect of any game outcomes. Since the final outcomes of the 1 PM and 4 PM games are still unknown at $3 \mathrm{PM}$, this is consistent with the assumption that it is the game outcome that matters. By comparison, for the $3 \mathrm{PM}-6 \mathrm{PM}$ window (column 2) there is a significant upset loss effect for 1 PM games, but no significant effect for the 4 PM games. The 1 PM games end in this interval, while the 4 PM games are still going on, so again the pattern is consistent with a causal effect of the game outcome. Between 6 and 9 PM (column 3) there is no significant effect of an upset loss for the 1 PM games, but a sizeable effect (a significant $31 \%$ increase in violence) for the 4 PM games. Finally, during the 9 PM to midnight interval (column 4), neither of the two upset loss coefficients is statistically significant. In sum, while the standard errors are fairly large, especially for the less-numerous 4 PM games (which include only 16 upset losses and 13 upset wins), the data suggest that the spike in violence after an upset loss is concentrated in a narrow time window surrounding the end of the game.

\section{V.B. Emotionally Salient Games}

Assuming that the link between NFL game outcomes and violence arises through emotional cues, one might expect more "emotionally salient" games to have larger effects. The models in Table 6 explore the relative effects of game outcomes for more salient games (upper panel) and less salient games (lower panel) using the salience classifications introduced in

\footnotetext{
${ }^{21}$ As a robustness check, we explored whether violence is not due to upset losses per se but to game outcomes where the home team failed to "beat the spread." Specifically, we added a dummy equal to 1 if the actual point spread was less than the Las Vegas spread. In a model like the one in Table 4, column 3, the estimated effect is relatively small and insignificantly different from zero (estimate $=-$. 013 , s.e. $=.020)$.

${ }^{22}$ We do not try to fit separate coefficients for games starting at $8 \mathrm{PM}$, since there are very few of these games (6\% of the sample), and until 2006 they were only shown on cable or satellite.
} 
Table $3 .{ }^{23}$ In column 1, we define salience by whether the home team is still in playoff contention (based on having at least a 10\% chance of making the playoffs). Among such games the effect of an upset loss rises to $13 \%$, while the effect of a close loss rises to $5 \%$ and is marginally significant $(\mathrm{t}=1.8)$. In contrast, when the home team is no longer in playoff contention the effect of an upset loss is small and statistically insignificant. The effects of upset losses in the two types of games are statistically different from each other at the $11 \%$ level (third-last row of the table).

Column 2 looks at games against a traditional rival team. The effect of an upset loss is about twice as large for a rivalry game compared to a non-rivalry game (20\% versus $8 \%$, p-value for test of equality $=0.01$ ). There is also a marginally significant increase in violence following an upset win against a rival $(\mathrm{t}=2.0)$, a pattern that is inconsistent with our simple emotional cueing model.

Upset losses in games that are particularly frustrating for fans could also generate a larger emotional response. In column 3 we look at the effects of three potentially frustrating occurrences: 4 or more sacks, 4 or more turnovers, or 80 or more penalty yards. At least one of these events happens in about $40 \%$ of the games in our sample. For frustrating games defined in this manner, the estimated effect of an upset loss is 15\%, compared with an estimated $7 \%$ increase in violence for upset losses in non-frustrating games.

In the final column of Table 6, we narrow the focus to the $37 \%$ of games where the home team is still in playoff contention and is either playing a traditional rival or the game involved an unusual number of sacks, turnovers, or penalties. The effect of an upset loss is now a $17 \%$ increase in IPV, compared to a $13 \%$ increase for all playoff-contention games in column 1. Moreover, the effect of an upset loss is very close to zero for games which do not fit these criteria. (In fact none of the spread or outcome interaction coefficients are large or significant for these games). These patterns suggest that the overall rise in IPV following an upset loss is driven entirely by losses in games that "matter" the most to fans. ${ }^{24}$

\section{V.C. Alternative Parameterization}

The models in Tables 4-6 all control for the pre-game point spread using a simple set of indicators for 3 ranges of the spread. As an alternative, we fit a set of models with a second order polynomial in the point spread, and an interaction between the polynomial and a dummy for a home team loss. Consistent with our baseline specifications, the results show that the effect of a home team loss on intimate partner violence is large and positive when the home team is expected to win, and declines steady as the expected likelihood of a home team victory increases. This pattern is also present when we limit attention to "highly salient" games, defined as in column 4 of Table 6 . Figure 5 shows the estimated interaction effects for highly salient games, along with the associated (point-wise) $95 \%$ confidence intervals. For highly salient games with pre-game point spreads less than -2 or so, the effect of a loss is positive and significantly different from zero. For predicted close games and predicted losses, the effects of a loss are insignificantly different from zero.

\section{V.D. Updating of the Reference Point for Game Outcomes}

So far we have assumed that family violence is related to the gap between actual game outcomes and fans' pre-game expectations. Over the roughly 3 hours that a game actually occurs, however, fans receive new information about the likelihood of final victory, and it is

\footnotetext{
${ }^{23} \mathrm{We}$ fit the models in each column with a full set of interactions between the salience indicator and the 6 dummies representing the pre-game spread and its interaction with the game outcome.

${ }^{24}$ It is also possible that conditional on the point spread, more violent men are more likely to watch pivotal games (although the amount of selection would have to be sizeable).
} 
interesting to ask whether the reference point for the emotional cue of the final outcome adjusts accordingly. Some stickiness would seem to be required to generate the pattern of effects in Table 5, which shows little or no reaction while a game is in progress, but a rise in violence following an upset loss. Since many of these losses would be predictable midway through the game, if fans actually updated their reference point the final score would not be a surprise. To address the question more formally, we use information on the score at halftime to form an updated spread, and ask whether the rise in violence following a loss is better explained by pre-game expectations, or those as of halftime.

To proceed, let $p_{O}$ denote the probability of a home team victory based on the pre-game spread, and let $p_{1}$ denote the point spread at half-time (i.e., the actual point difference at halftime). Assume that the emotional cue generated by the game outcome $(y)$ is based on the deviation from an updated reference point:

$$
p^{*}=\delta p_{1}+(1-\delta) p_{0}
$$

With fully rational updating $\delta$ would be equal to the coefficient of the halftime spread in a regression of the probability of ultimate victory on the pre-game and halftime spreads (which is approximately 0.6 ), while with rigid expectations $\delta=0 .{ }^{25}$ Substituting this expression into equation (3), the predicted difference in the risk of violence after a loss versus a win becomes

$$
\Delta(\operatorname{risk} \mid p)=\left[\beta+(\alpha-\beta) \delta p_{1}+(\alpha-\beta)(1-\delta) p_{0}\right] q . \quad\left(3^{\prime}\right)
$$

Consideration of this expression suggests that we extend our basic model by including a second set of indicators for upset loss, upset win, etc., based on the halftime spread.

Estimation results from two alterative variants of this extended specification are presented in Table 7. Because of perfect co-linearity, we cannot simply replicate our baseline models by adding dummies for the 3 ranges of the halftime spread, and a full set of interactions with a loss or win dummy. ${ }^{26}$ One estimable specification, which drops the main effects for the range of the half-time spread, is presented in the first column of the table. In this specification the estimated interactions with the predicted outcomes based on the pre-game spread are all very similar to the estimates from our baseline model, whereas the interactions with the predicted outcomes based on the halftime spread are all small and insignificant (individually and jointly). Results from an alternative, and more parsimonious specification are presented in columns 2 and 3. Here, we include a linear control for the spread and a dummy for non-game days, rather than dummies for the range of the spread. As a check on the validity of this simpler specification, the model in column 2 excludes all the halftime variables. As in our baseline models, this simple specification shows a roughly $10 \%$ effect of upset losses, and small and insignificant effects of upset wins and close loses. Column 3 extends this model by adding dummies for upset win, upset loss, and close loss, based on predictions using the halftime spread. As in column 1, the halftime variables are jointly insignificant $(\mathrm{p}=0.50)$ though the point estimates are somewhat larger in magnitude. Based on the results from these two specifications, we conclude that fans' emotional reactions to

\footnotetext{
${ }^{25}$ Appendix Table 1 presents a series of models that relate the probability of a home team win to the pregame spread and the halftime spread. Both are highly significant predictors: the relative magnitude of the halftime spread compared to the pre-game spread is approximately 0.6 . We also fit models that divide the pre-game and halftime spread into 3 ranges (with cutoffs at -4 and 4 points). In these models the relative magnitudes of the halftime dummies are also about 60 percent of the combined magnitude.

${ }^{26}$ Our baseline model includes dummies for three ranges of the pre-game spread $\left(\mathrm{S}_{1}, \mathrm{~S}_{2}, \mathrm{~S}_{3}\right)$, and interactions of these with a loss dummy (L), treating non-game days as the base case. Call the additional indicators for the halftime spread $\left(\mathrm{H}_{1}, \mathrm{H}_{2}, \mathrm{H}_{3}\right)$. Since $\mathrm{S}_{1}+\mathrm{S}_{2}+\mathrm{S}_{3}=\mathrm{H}_{1}+\mathrm{H}_{2}+\mathrm{H}_{3}=1$, the set of 12 variables $\left(\mathrm{S}_{1}, \mathrm{~S}_{2}, \mathrm{~S}_{3}\right),\left(\mathrm{H}_{1}, \mathrm{H}_{2}, \mathrm{H}_{3}\right),\left(\mathrm{S}_{1} \times \mathrm{L}, \mathrm{S}_{2} \times \mathrm{L}, \mathrm{S}_{3} \times \mathrm{L}\right),\left(\mathrm{H}_{1} \times \mathrm{L}, \mathrm{H}_{2} \times \mathrm{L}, \mathrm{H}_{3} \times \mathrm{L}\right)$ has only 9 degrees of freedom.
} 
game outcomes appear to be driven by the game outcome relative to expectations at the start of the game, with little or no updating using information as of halftime.

\section{V.E. Other Forms of Family Violence, Alcohol and Drug Use, Severity of Violence}

As noted in Table 1, the most common family violence incidents are those committed at home by men against their wives and girlfriends. While our main results concern these types of incidents, we also examined the effects of NFL game outcomes on family violence committed in different places, and involving different combinations of victims and offenders. The results are summarized in Appendix Table 2 (available in the online appendix). We find that upset losses have no significant effect on away-from-home violence. As a result, the effect on total male-on-female violence (combining at-home and away-from-home) is somewhat smaller than the effect on at-home violence (around 7\%). We also find that NFL game outcomes have no large or significant effect on the rate of intimate partner violence committed by women. On the other hand, violence by men against wives and girlfriends both respond about equally to upset losses. Rates of violence against family members other than an intimate partner (e.g., a child, sibling, or parent) also show no significant relationship with the outcomes of local NFL games, while there is some indication of an effect on rates of violence at home against friends.

To gain some insights into the kinds of incidents that are most affected by the emotional cues of NFL game outcomes, we fit separate Poisson models for incidents with alcohol and/ or drugs involved, and for serious versus minor assaults. ${ }^{27}$ The results, summarized in Appendix Table 3 of the online appendix, suggest that all forms of IPV rise following an upset loss, with no significant difference in the rise in alcohol-related and non-alcoholrelated offenses. We also looked at incidents occurring in larger and smaller places (populations over and under 50,000 as of the year 2000) and incidents committed by younger and older offenders (less than age 30 versus 30 or older), and found insignificantly different effects of upset losses.

\section{V.F. Other Robustness Tests}

Finally, we have conducted a number of additional specification checks to judge the robustness of our main results. These are summarized in Appendix Table 4 of the online appendix. The specification checks include the use of a Negative Binomial model instead of a Poisson, estimation of models with date fixed effects, and inclusion of separate linear time trends for each of the individual teams in our sample. None of these changes has much impact on our main results. We also investigated different ways of dealing with the presence of days with no reported crime in the NIBRS data. Reassuringly, our main results are very similar, regardless of whether we treat these "no crime" days as missing or true zeros.

\section{DISCUSSION}

Our empirical results show a roughly $10 \%$ effect of an upset loss by the local NFL team on the rate of male-on-female at-home intimate partner violence. To provide some context for the magnitude of this effect we estimated a set of Poisson models for the rate of IPV on all days of the year for the 6 states of our estimation sample. These models included agency fixed effects, an expanded set of holiday dummies, dummies for the day of the week, the month, and the sample year, and the same set of weather controls included in our main models. ${ }^{28}$ The resulting estimates show large and precisely estimated effects of major

\footnotetext{
${ }^{27}$ Recall that in about $20 \%$ of incidents the reporting officer notes that alcohol or drugs were a contributing factor in the incident these are the incidents with "alcohol involved". Serious assaults include aggravated assaults and all other incidents in which the victim was physically injured.
} 
holidays on the rate of IPV: for example, Christmas day $+18 \%$, Thanksgiving $+20 \%$, Memorial Day $+30 \%$, New Year's Day $+31 \%$, New Year's Eve $+22 \%$, and July $4^{\text {th }}+29 \%$. They also show a significant positive effect of hotter weather: relative to a day with a maximum temperature less than 80 degrees, IPV is $8 \%$ higher when the maximum temperature is over 80 . Thus, an upset loss is comparable to the effect of a hot day, or about one-third of the effect of a holiday like Memorial Day or the Fourth of July. We view the magnitude of the cueing effect attributable to an upset loss as rather large, considering that only a fraction of the population are serious football fans, and that our sample largely excludes the cities in which the NFL teams are located.

Our findings add to the literature on the impact of media on violence and the wellbeing of women. Television has been shown to influence a variety of behaviors and attitudes, including fertility choices, women's status, and the acceptability of intimate partner violence (La Ferrara et al., 2008; Jensen and Oster, 2009). As emphasized by Dahl and DellaVigna (2009), media (in particular, violent movies) affects behavior not only via content, but also because it changes time spent in alternative activities. In our case, NFL football games are likely to bring couples together, and the emotional cues associated with televised games place women at an elevated risk of abuse.

From a broader perspective, our analysis contributes to the growing literature on the importance of reference points in observed behavior (see DellaVigna, 2009 for a review; Crawford and Meng, 2009 for a recent empirical contribution; and Abeler et al. 2009 for a recent laboratory experiment). A key advantage of our setting is that the "rational" reference points for NFL game outcomes are readily observable, and vary widely across games. Our finding that upset losses have a large effect on family violence, whereas losses in games that were expected to be close have small and insignificant effects, provides confirmation of rational reference point formation. In comparison to the large and systematic effects of upset losses we also find very small effects from upset wins, suggesting that gains and losses have asymmetric behavioral effects.

UC Berkeley and NBER

UC San Diego and NBER

\section{Supplementary Material}

Refer to Web version on PubMed Central for supplementary material.

\section{References}

Abeler, Johannes; Falk, Armin; Gotte, Lorenz; Huffman, David. Reference Points and Effort Provision. IZA Discussion Paper No. 3939. 2009

Aizer, Anna. The Gender Wage Gap and Domestic Violence. American Economic Review. 2010 forthcoming.

Ariely, Dan; Loewenstein, George. In the Heat of the Moment: The Effect of Sexual Arousal on Sexual Decision Making. Journal of Behavioral Decision Making. 2005; 18(1):1-12.

Baumeister, Roy F.; Heatherton, Todd F. Self Regulation Failure: An Overview. Psychological Inquiry. 1996; 7(1):1-15.

Bernheim, B Douglas; Rangel, Antonio. Addiction and Cue-Triggered Decision Responses. American Economic Review. 2004 Dec.94:1558-1590.

\footnotetext{
${ }^{28}$ These models, like our main results in Table 4, were fit using data on male-on-female at-home incidents from noon to midnight only.
} 
Bloch, Francis; Rao, Vijayendra. Terror as a Bargaining Instrument: A Case Study of Dowry Violence in Rural India. American Economic Review. 2002 Sep.92:1029-1043.

Bowlus, Audra; Seitz, Shannon. Domestic Violence, Employment and Divorce. International Economic. 2006 Nov.:1113-1149. Review 47.

Cameron, A Colin; Trivedi, Pravin K. Econometric Models Based on Count Data: Comparisons and Applications of Some Estimators and Tests. Journal of Applied Econometrics. 1986 Jan.1:29-53.

Cameron, A Colin; Trivedi, Pravin K. Regression Analysis of Count Data. Cambridge University Press; 1998.

Card, David; Dahl, Gordon B. Family Violence and Football: The Effects of Unexpected Emotional Cues on Violent Behavior. National Bureau of Economic Research Working Paper No. 15497. 2009

Chwe, Michael. Why Were Workers Whipped? Pain in a Principal-Agent Model. Economic Journal. 1990 Dec.100:1109-1121.

Crawford, Vincent; Meng, Juanjuan. New York City Cabdrivers' Labor Supply Revisited: ReferenceDependent Utility with Targets for Hours and Income. UC San Diego Department of Economics Unpublished Working Paper. 2009.

Dahl, Gordon; DellaVigna, Stefano. Does Movie Violence Increase Violent Crime? Quarterly Journal of Economics. 2009 May.124:677-734.

DellaVigna, Stefano. Psychology and Economics: Evidence from The Field. Journal of Economic Literature. 2009 Jun.47:315-372.

Dobash, Russell E.; Dobash, Rebecca. Violence Against Wives. New York: Free Press; 1979.

Durose, Matthew R.; Harlow, Caroline Wolf; Langan, Patrick A.; Motivans, Mark; Rantalal, Ramona R.; Smith, Erica L. U.S. Department of Justice Office of Justice Programs Report No. NCJ 207846. Washington D.C.: USGPO; 2005 Jun. Family Violence Statistics.

Exum, M Lyn. The Application and Robustness of the Rational Choice Perspective in the Study of Intoxicated and Angry Intentions to Aggress. Criminology. 2002; 40(4):933-966.

Farmer, Amy; Tiefenthaler, Jill. An Economic Analysis of Domestic Violence. Review of Social Economy. 1997; 55(3):337-358.

Fox, James Alan; Zawitz, Marianne W. United States Department of Justice Bureau of Justice Statistics. Washington D.C.: National Archive of Criminal Justice Statistics; 2007. Homicide Trends in the United States.

Gandar, John; Zuber, Richard; O’Brien, Thomas; Russo, Ben. Testing Rationality in the Point Spread Betting Market. Journal of Finance. 1988; 43(4):995-1008.

Gantz, Walter; Bradley, Samuel D.; Wang, Zheng. Televised NFL Games, the Family, and Domestic Violence. In: Raney, Arthur A.; Bryant, Jennings, editors. Handbook of Sports and Media. Mahwah, NJ: Lawrence Erlbaum Associates; 2006. p. 365-382.

Gelles, Richard J.; Straus, Murray A. Societal Change and Change in Family Violence from 1975 to 1986 as Revealed by Two National Studies. Journal of Marriage and the Family. 1986; 48:465479.

Hamby, Sherry L. Measuring Gender Differences in Partner Violence: Implications from Research on Other Forms of Violent and Socially Undesirable Behavior. Sex Roles. 2005 Jun.52:725-742.

Hirschel, David. Domestic Violence Cases: What Research Shows About Arrest and Dual Arrest Rates. National Institute of Justice Research Report. 2008

Jensen, Robert; Oster, Emily. The Power of TV: Cable Television and Women's Status in India. Quarterly Journal of Economics. 2009 Aug.124:1057-11094.

Johnson, Michael P. Patriarchal Terrorism and Common Couple Violence: Two Forms of Violence Against Women. Journal of Marriage and the Family. 1995; 57(2):283-294.

Johnson, Michael P. Differentiating Among Types of Domestic Violence: Implications for Healthy Marriages. In: Peters, H Elizabeth; Kamp Dush, Clarie M., editors. Marriage and Family: Perspectives and Complexities. New York: Columbia University Press; 2009. 2009

Klosterman, Keith C.; Fals-Stewart, William. Intimate Partner Violence and Alcohol Use: Exploring the Role of Drinking in Partner Violence and its Implications for Intervention. Aggression and Violent Behavior. 2006; 11(6):587-597. 
Koszegi, Botond; Rabin, Matthew. A Model of Reference-Dependent Preferences. Quarterly Journal of Economics. 2006 Nov.121:1133-1165.

Laibson, David. A Cue-Theory of Consumption. Quarterly Journal of Economics. 2001 Feb.116:81119.

La Ferrara, Eliana; Chong, Alberto; Duryea, Suzanne. Soap Operas and Fertility: Evidence from Brazil. BREAD Working Paper No. 172. 2008

Levitt, Steven. Why are Gambling Markets Organized So Differently From Financial Markets? Economic Journal. 2004 Apr.114:223-246.

Loewenstein, George. Emotions in Economic Theory and Economic Behavior. American Economic Review. 2000 May.90:426-432.

Loewenstein, George; O'Donoghue, Ted. The Heat of the Moment: Modeling Interactions Between Affect and Deliberation. Carnegie Mellon University Department of Social and Decisions Sciences Unpublished Working Paper. 2007 Mar.

Lutmer, Erzo. Neighbors as Negatives: Relative Earnings and Well-Being. Quarterly Journal of Economics. 2005 Aug.120:963-1002.

Pankoff, Lyn D. Market Efficiency and Football Betting. Journal of Business. 1968 Apr.41:103-114.

Rand, Michael R. Callie Marie Rennison. Bigger is Not Necessarily Better: An Analysis of Violence Against Women Estimates from the National Crime Victimization Survey and the National Violence Against Women Survey. Journal of Quantitative Criminology. 2005 Sep.21:267-291.

Rees, Daniel I.; Schnepel, Kevin T. College Football Games and Crime. Journal of Sports Economics. 2009; Vol. 10:68-86.

Straus, Murray A.; Gelles, Richard J.; Steinmetz, Susan K. Behind Closed Doors: Violence in the American Family. Garden City, N.Y.: Anchor/Doubleday; 1980.

Tauchen, Helen V.; Witte, Anne Dryden; Long, Sharon K. Domestic Violence: A Non-random Affair. International Economic Review. 1991; 32:491-511.

Thaler, Richard H.; Shefrin, HM. An Economic Theory of Self Control. Journal of Political Economy. 1981 May.89:392-406.

Vazquez, Salvador; Stohr, Mary K.; Purkiss, Marcus. Intimate Partner Violence Incidence and Characteristics: Idaho NIBRS 1995-2001 Data. Criminal Justice Policy Review. 2005 Mar.16:99_ 114.

Wilt, Susan; Olson, Sarah. Prevalence of Domestic Violence in the United States. Journal of the American Medical Women's Association. 1996 May-Jun;51:77-82.

Wolfers, Justin; Zitzewitz, Eric. Interpreting Prediction Markets as Probabilities. University of Pennsylvania Wharton School, Unpublished Working Paper. 2007 Jan. 
Figure I: Risk of Violence Following Loss or Win

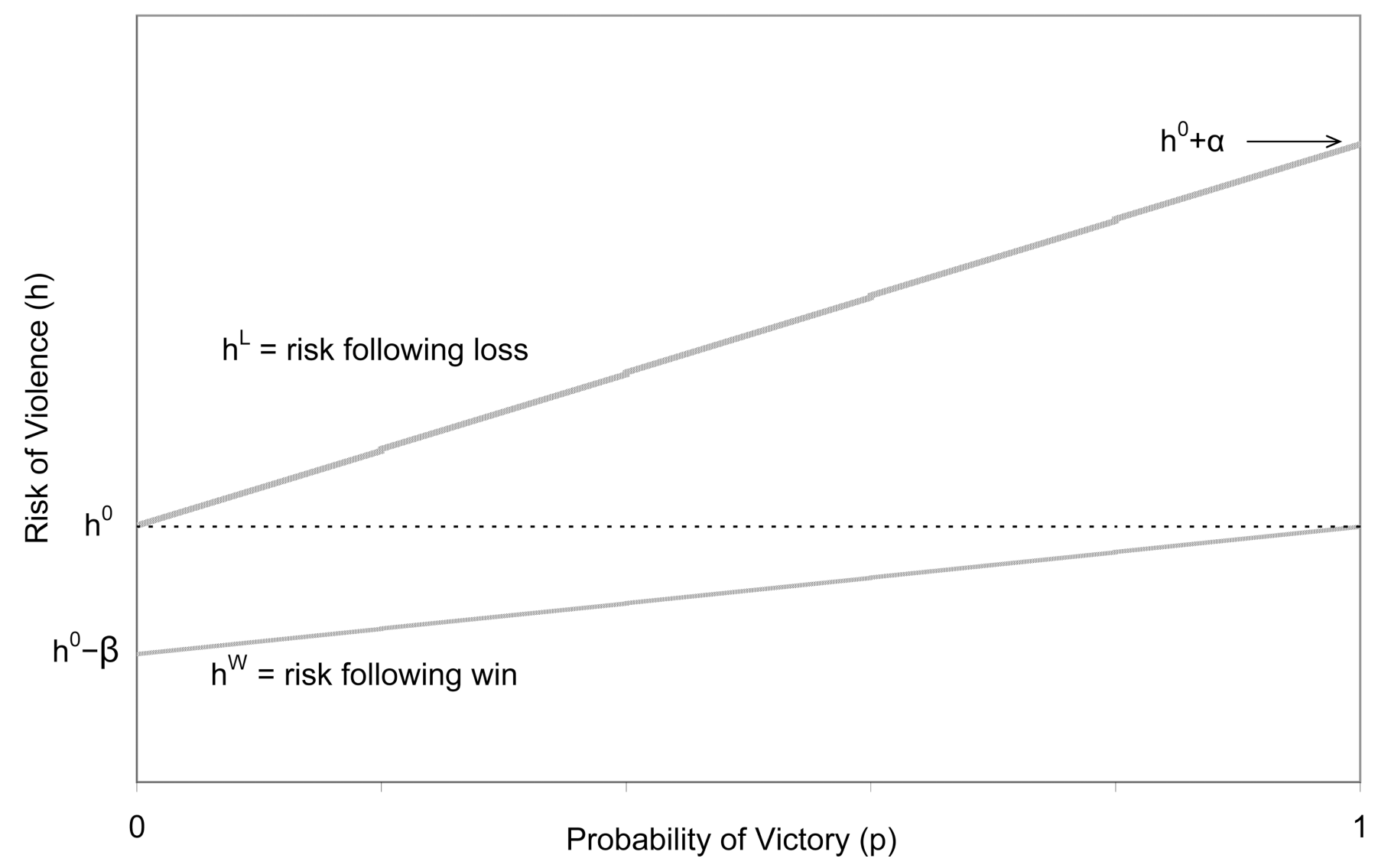

Figure I.

Risk of Violence Following Loss or Win 


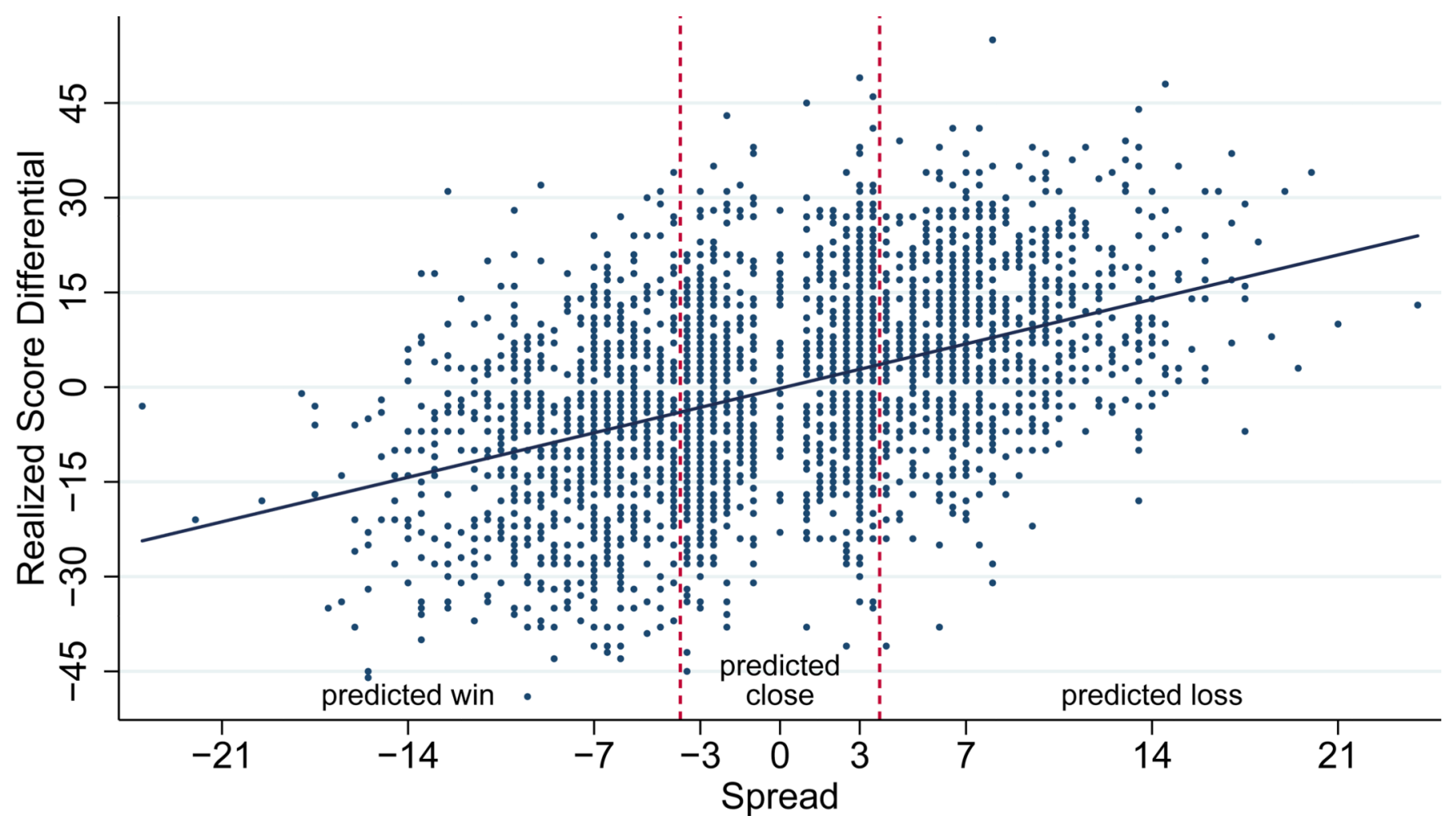

Figure II.

Final Score Differential versus the pre-Game Point Spread

Notes: Realized score differential is opponent's minus local team's final score. The plotted regression line has an intercept of -.17 (s.e.=.21) and a slope of 1.01 (s.e.=.03). 


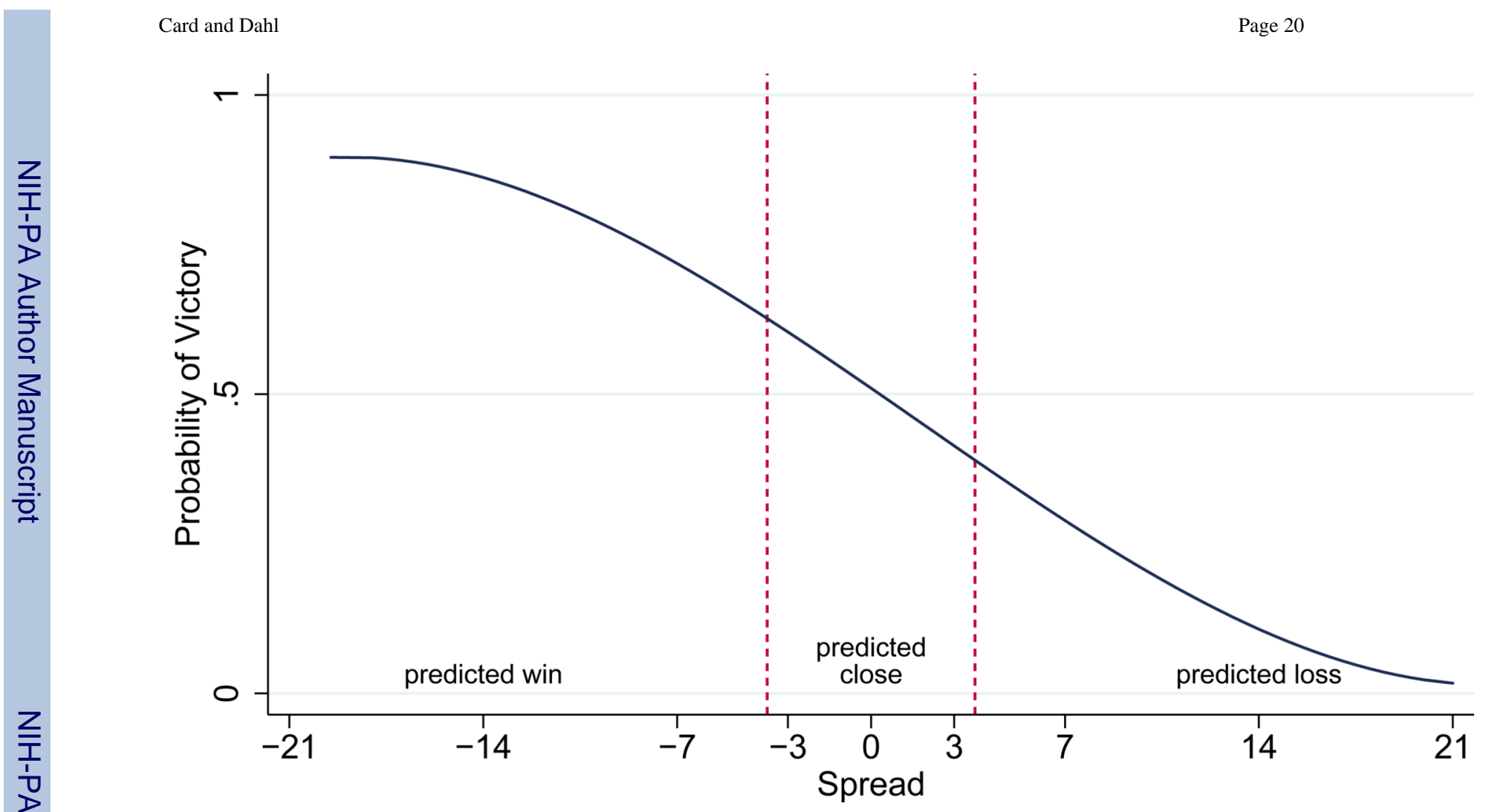

Figure III.

Probability of Victory as a Function of the Spread

Note: Curve is fit from a regression of the probability of victory for the local team on a third order polynomial in the spread. 


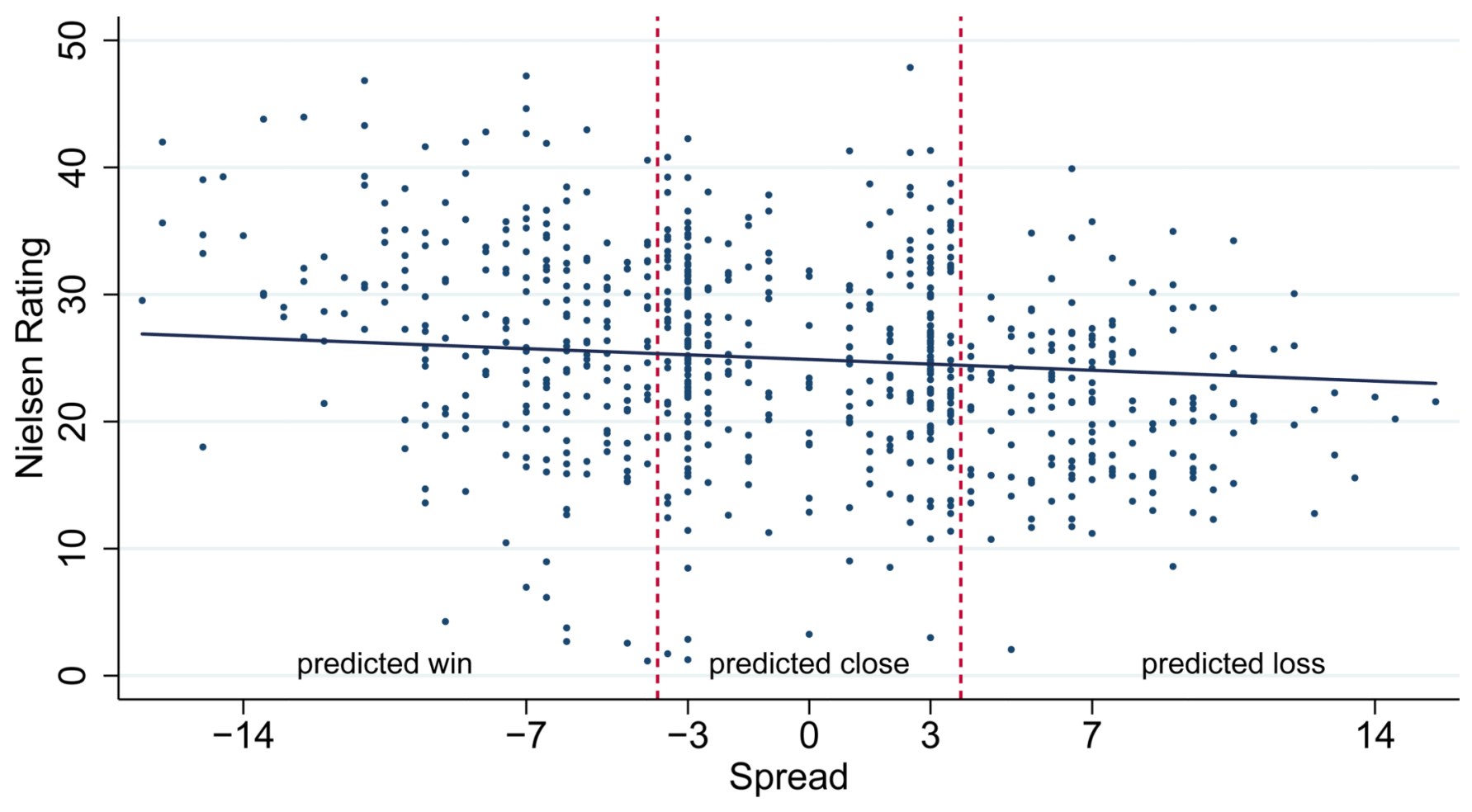

Figure IV.

Television Audience for Local Games and the Spread

Note: Each rating point equals $1 \%$ of the total number of television households in the local market. The plotted regression line controls for team fixed effects and has an intercept of 24.89 (s.e.=.20) and a slope of -.12 (s.e.=.03). 


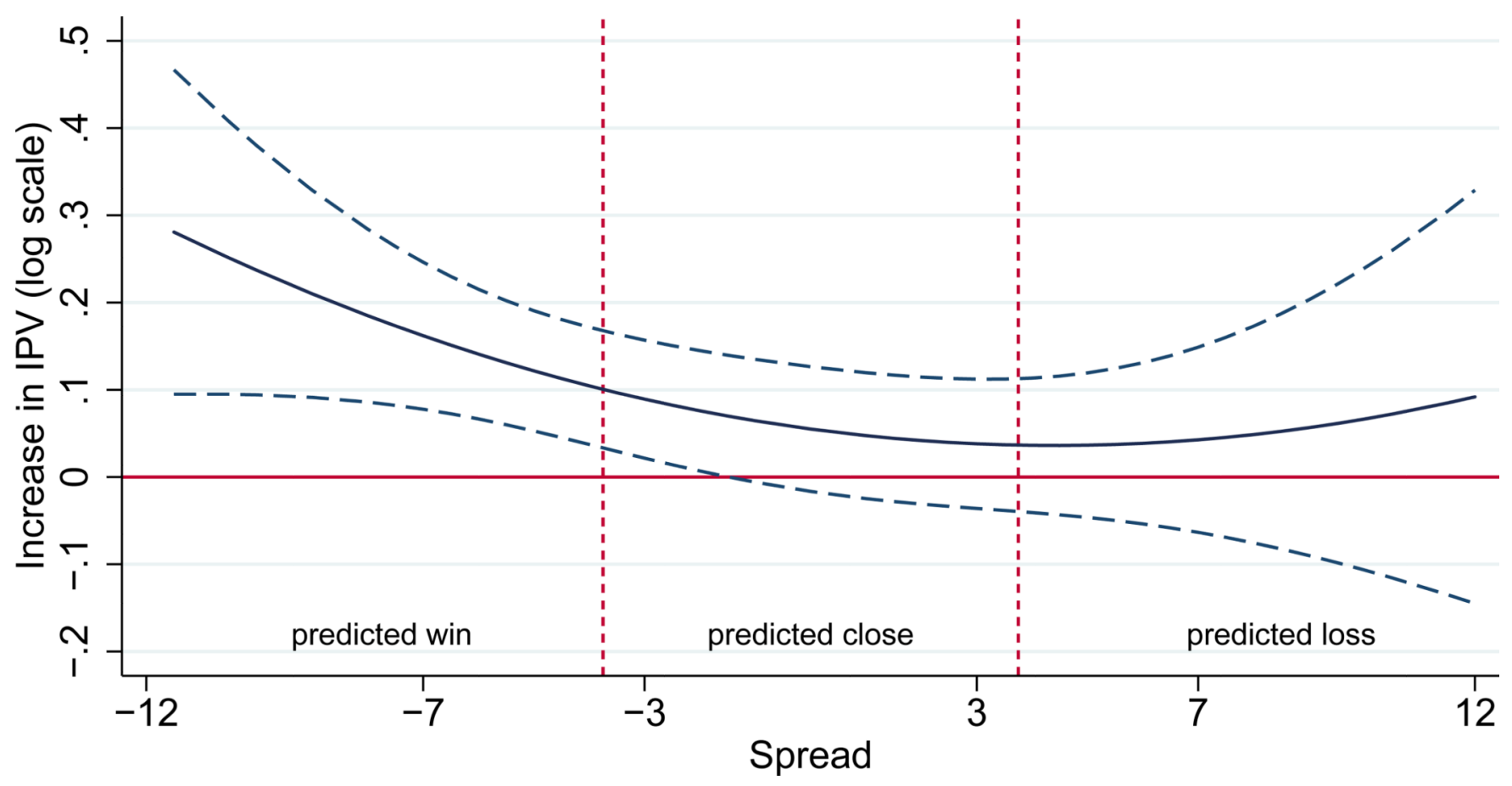

Figure V.

Differential Increase in Violence for a Loss versus a Win, as a Function of the Spread, For Highly Salient Games

Notes: Dashed lines are pointwise $95 \%$ confidence intervals. Highly salient games include games in which the local team is still in playoff contention and also is playing against a traditional rival or has an unusually large number of sacks, turnovers, or penalties (see Table 6). 
Table I

Summary Statistics for Intimate Partner Violence, NIBRS data, 1995-2006.

\begin{tabular}{|c|c|c|}
\hline Intimate Partner Violence & $\begin{array}{l}\text { Daily Rate for the hours of } \\
12 \text { PM to 11:59 PM } \\
\text { Per 100,000 Population }\end{array}$ & $\begin{array}{l}\text { Fraction in Category } \\
\text { or Subcategory }\end{array}$ \\
\hline \multicolumn{3}{|c|}{ A. Sundays During Regular Football Season } \\
\hline \multicolumn{3}{|l|}{$\underline{\text { Location and Victim-Offender Relationship }}$} \\
\hline All Intimate Partner Violence & 1.28 & 1.00 \\
\hline Male on Female & 1.04 & .81 \\
\hline Occurring at Home & .85 & .82 \\
\hline Against Wife & .46 & .54 \\
\hline Against Girlfriend & .39 & .46 \\
\hline Occurring Away from Home & .19 & .18 \\
\hline Female on Male & .24 & .19 \\
\hline Occurring at Home & .19 & .79 \\
\hline Occurring Away from Home & .05 & .21 \\
\hline \multicolumn{3}{|c|}{ B. Sundays During Regular Football Season, Male on Female, Occurring at Home } \\
\hline \multicolumn{3}{|l|}{ Time of Day (all times Eastern Time) } \\
\hline $12 \mathrm{PM}$ to $2: 59 \mathrm{PM}$ & .16 & .19 \\
\hline $3 \mathrm{PM}$ to 5:59 PM & .18 & .22 \\
\hline $6 \mathrm{PM}$ to $8: 59 \mathrm{PM}$ & .25 & .29 \\
\hline $9 \mathrm{PM}$ to $11: 59 \mathrm{PM}$ & .25 & .30 \\
\hline \multicolumn{3}{|l|}{ Alcohol Use and Assault Severity } \\
\hline Alcohol Involved & .17 & .20 \\
\hline Minor Assault & .41 & .48 \\
\hline Serious Assault & .44 & .52 \\
\hline \multicolumn{3}{|l|}{ Agency Size } \\
\hline Smaller Cities or Counties (pop<50K) & .89 & .47 \\
\hline Larger Cities or Counties (pop $\geq 50 \mathrm{~K}$ ) & .73 & .53 \\
\hline \multicolumn{3}{|l|}{$\underline{\text { Age }}$} \\
\hline Younger Offenders $($ age $<30)$ & .32 & .38 \\
\hline Older Offenders (age $\geq 30$ ) & .52 & .61 \\
\hline
\end{tabular}

Notes: Data are reports of intimate partner violence to local police agencies in the National Incident-Based Reporting System (NIBRS) for the states and years listed in Table 2. Intimate partner is defined as a spouse (including common law and ex-spouse) or a boyfriend/girlfriend. Violence is defined as aggravated assault, simple assault, or intimidation. Alcohol involved indicates the reporting officer noted that either alcohol or drugs were a contributing factor. Minor assault is simple assault or intimidation without injury; serious assault is aggravated assault or any assault with a physical injury. Category fractions for agency size are weighted by the average population in smaller versus larger cities and counties. 


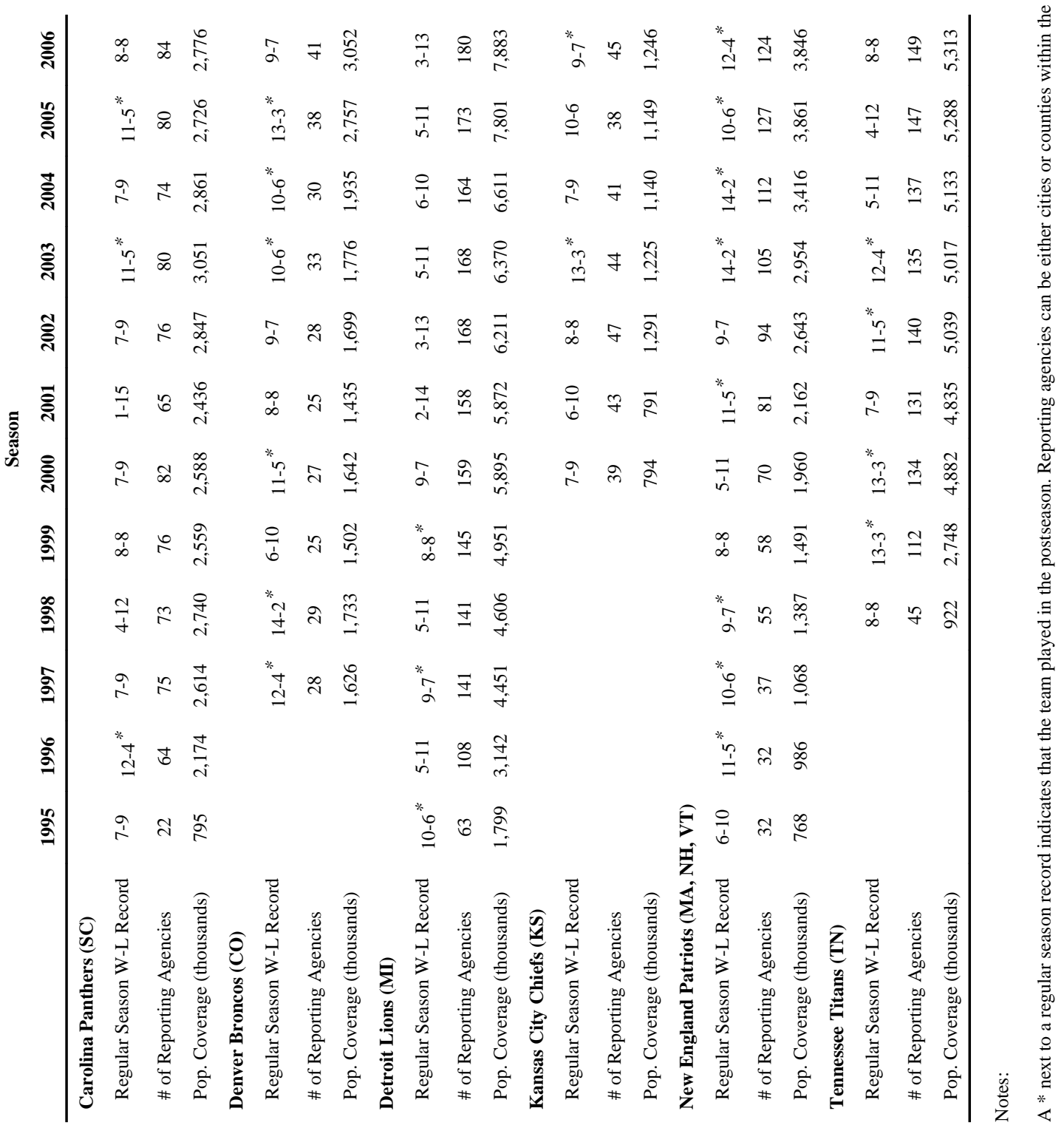


Table III

Summary Statistics for NFL Football Games and Nielsen Television Ratings.

A. All NFL Football Games, 1995-2006

Day of Week and Season/Postseason

$\begin{array}{lcc}\text { Regular Season Games } & 993 & .95 \\ \text { Sunday Games } & 866 & .87 \\ \text { Monday Night Football } & 68 & .07 \\ \text { Thursday, Friday, or Saturday Games } & 59 & .06 \\ \text { Postseason Games (36 on Sunday, 17 on Saturday) } & 53 & .05\end{array}$

B. Sunday Regular Season NFL Games, 1995-2006

Outcome

$\begin{array}{lll}\text { Loss } & 414 & .48 \\ \text { Win } & 452 & .52\end{array}$

Predicted and Actual Outcomes Based on Pre-Game Point Spread

Predicted Win: Point Spread $\leq 4$

283.33

Actual Loss (Upset Loss)

$79 \quad .28$

Predicted Close: $-4<$ Point Spread $<4$

$377 \quad .44$

Actual Loss (Close Loss)

$194 \quad .49$

Predicted Loss: Point Spread $\geq 4$

$206 \quad .24$

Actual Win (Upset Win)

65

.32

Predicted and Actual Outcomes Based on Halftime Point Spread

Predicted Win: Halftime Point Spread $\leq 4$

$338 \quad .39$

Actual Loss (Halftime Upset Loss)

$61 \quad .18$

Predicted Close: $-4<$ Halftime Point Spread $<4$

$240 \quad .28$

Actual Loss (Halftime Close Loss)

$126 \quad .53$

Predicted Loss: Halftime Point Spread $\geq 4$

$288 \quad .33$

Actual Win (Halftime Upset Win)

61

.21

No Sunday Game

Played on Another Day of the Week

"Bye" Week

62

.33

By Time of Day

1 PM ET Start Time

$\begin{array}{cl}587 & .68 \\ 224 & .26 \\ 55 & .06\end{array}$

8 PM ET Start Time

5

.06

\section{$\underline{\text { Salient Games }}$}
(a) Still in Playoff Contention
$589 \quad .68$
(b) Against a Traditional Rival
201
.23
(c) Sacks $\_4$, Turnovers $\underline{4}$, or Penalties $>80$ yds
$341 \quad .39$
(d) Highly Salient: (a) and [(b) or (c)]
321
.37

C. Nielsen Media Research Local Television Ratings, 1997-2006 


\begin{tabular}{lcc}
\hline & $\begin{array}{c}\text { Number } \\
\text { of Games }\end{array}$ & $\begin{array}{c}\text { Fraction in Category } \\
\text { or Subcategory }\end{array}$ \\
\cline { 2 - 3 } Percent of Local TV Households Watching Game & Average (\%) & Max (\%) \\
\cline { 2 - 3 } Local Team Playing & 24.3 & 47.9 \\
1 PM Game & 23.1 & 47.2 \\
Local Team Playing & 8.1 & 17.7 \\
Local Team not Playing that Sunday & & \\
4 PM Game & 29.4 & 47.9 \\
Local Team Playing & 12.3 & 22.2 \\
Local Team not Playing that Sunday & & \\
8 PM Game (ESPN/TNT games only) & 10.1 & 19.0 \\
Local Team Playing & 8.3 & 21.4 \\
Local Team not Playing that Sunday & & \\
\hline
\end{tabular}

Notes: Sample covers the teams and years listed in Table 2. Starting times of games are approximate. See notes to Table 6 for definitions of salient games. Nielsen ratings begin in 1997 for Carolina, Denver, Detroit, and New England; 1998 for Tennessee; and 2000 for Kansas. Ratings for the 8 PM games do not include the 2006 season, as the broadcasts switched from cable/satellite (ESPN/TNT) to an over the air network (NBC) in 2006. Average ratings for 8 PM games in 2006 are $33.9 \%$ and $9.1 \%$ when the local team is playing and not playing, respectively 


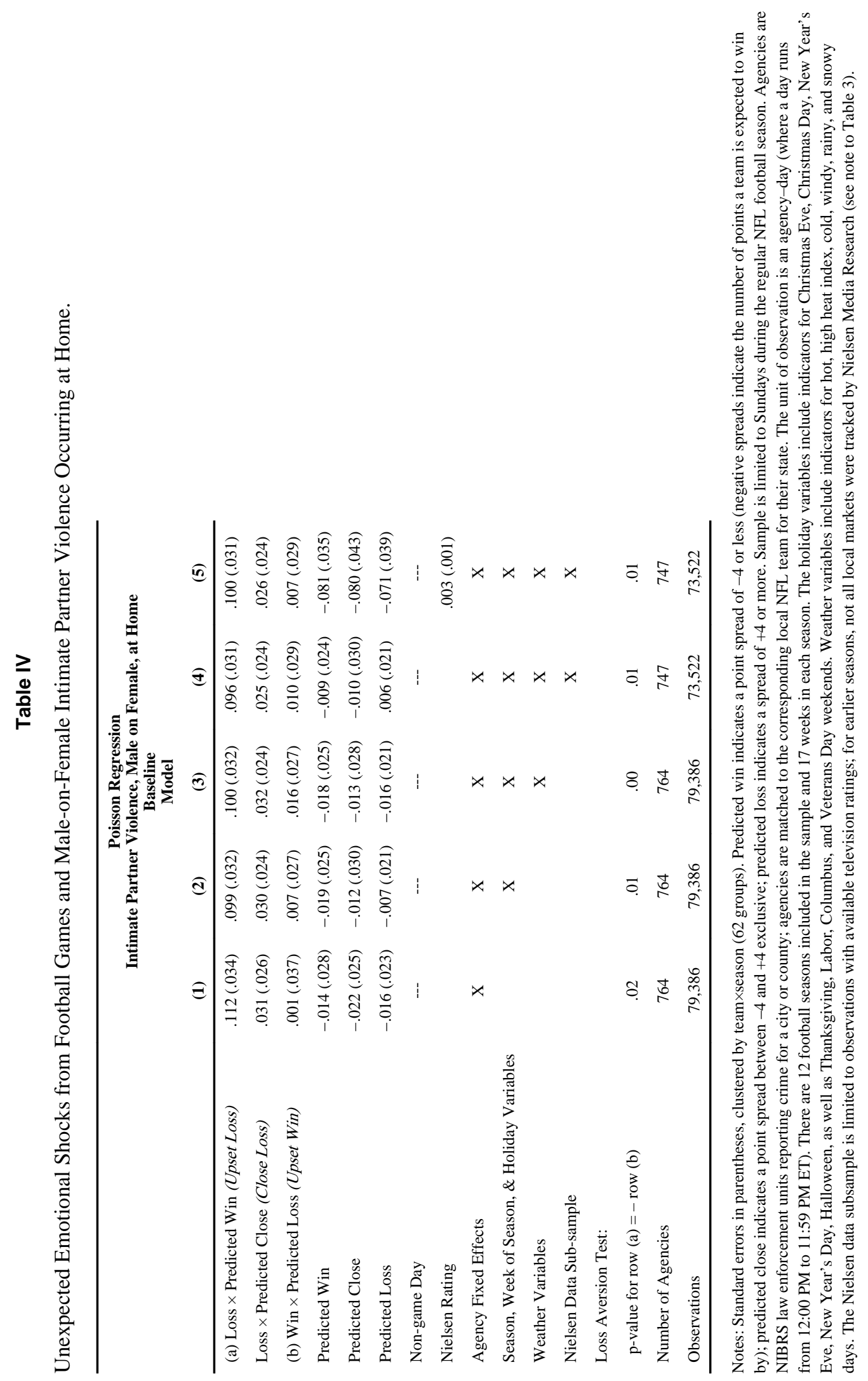


Table V

Timing of Shocks and Violence.

\begin{tabular}{|c|c|c|c|c|}
\hline & \multicolumn{4}{|c|}{$\begin{array}{l}\text { Poisson Regression } \\
\text { Intimate Partner Violence, Male on Female, at Home } \\
\text { Assaults Occurring between (Eastern Time): }\end{array}$} \\
\hline & $\begin{array}{c}12 \mathrm{PM} \text { to } 3 \mathrm{PM} \\
\text { (1) }\end{array}$ & $\begin{array}{c}3 \text { PM to } 6 \text { PM } \\
\text { (2) }\end{array}$ & $\begin{array}{c}6 \text { PM to } 9 \text { PM } \\
\text { (3) }\end{array}$ & $\begin{array}{c}9 \text { PM to } 12 \mathrm{AM} \\
\text { (4) }\end{array}$ \\
\hline \multicolumn{5}{|l|}{ Games starting at $1 \mathrm{PM}$} \\
\hline Loss $\times$ Predicted Win (Upset Loss) & $.075(.075)$ & $.200(.057)$ & $.036(.071)$ & $.075(.073)$ \\
\hline Loss $\times$ Predicted Close (Close Loss) & $.012(.058)$ & $-.002(.065)$ & $-.013(.056)$ & $.077(.050)$ \\
\hline Win $\times$ Predicted Loss (Upset Win) & $.017(.073)$ & $-.071(.067)$ & $-.006(.057)$ & $.036(.050)$ \\
\hline Predicted Win & $-.007(.105)$ & $-.140(.103)$ & $.070(.090)$ & $-.191(.095)$ \\
\hline Predicted Close & $.024(.097)$ & $-.075(.097)$ & $.049(.083)$ & $-.154(.097)$ \\
\hline Predicted Loss & $-.075(.087)$ & $-.039(.099)$ & $.029(.079)$ & $-.117(.085)$ \\
\hline Nielsen Rating & $.001(.004)$ & $.005(.004)$ & $-.002(.003)$ & $.006(.003)$ \\
\hline \multicolumn{5}{|l|}{ Games starting at $4 \mathrm{PM}$} \\
\hline Loss $\times$ Predicted Win (Upset Loss) & $.033(.182)$ & $.235(.216)$ & $.307(.167)$ & $.137(.170)$ \\
\hline Loss $\times$ Predicted Close (Close Loss) & $.064(.113)$ & $.211(.110)$ & $.016(.091)$ & $-.042(.103)$ \\
\hline Win $\times$ Predicted Loss (Upset Win) & $.115(.203)$ & $.121(.157)$ & $-.282(.124)$ & $.024(.121)$ \\
\hline Predicted Win & $-.188(.240)$ & $.035(.177)$ & $-.100(.160)$ & $-.040(.160)$ \\
\hline Predicted Close & $-.263(.213)$ & $-.117(.154)$ & $-.124(.129)$ & $-.083(.126)$ \\
\hline Predicted Loss & $-.073(.206)$ & $-.022(.133)$ & $-.096(.123)$ & $-.101(.128)$ \\
\hline Nielsen Rating & $.006(.007)$ & $-.002(.006)$ & $.006(.005)$ & $.004(.005)$ \\
\hline Non-game Day & --- & --- & --- & --- \\
\hline Number of Agencies & 563 & 591 & 619 & 620 \\
\hline Observations & 63,875 & 65,285 & 67,426 & 67,308 \\
\hline
\end{tabular}

Notes: Standard errors in parentheses, clustered by team×season. Regressions include agency fixed effects, season dummies, week of season dummies, and the holiday and weather variables described in the note to Table 4. Estimated models are comparable to the baseline model in column 3 of Table 4. See notes to Table 4 for details. Each column is a single regression for a given three-hour period and allows for separate coefficients for games starting at $1 \mathrm{PM}$ versus $4 \mathrm{PM}$. 


\section{Table VI}

Shocks from Emotionally Salient Games.

\begin{tabular}{|c|c|c|c|c|}
\hline & \multicolumn{4}{|c|}{$\begin{array}{c}\text { Poisson Regression } \\
\text { Intimate Partner Violence, Male on Female, at Home }\end{array}$} \\
\hline & $\begin{array}{c}\text { Game Type = } \\
\text { Still in Playoff } \\
\text { Contention } \\
\text { (1) }\end{array}$ & $\begin{array}{c}\text { Game Type }= \\
\text { Traditional } \\
\text { Rivals } \\
\text { (2) }\end{array}$ & $\begin{array}{c}\text { Game Type }= \\
\text { Sacks } \geq 4, \\
\text { Turnovers } \geq 4, \text { or } \\
\text { Penalties }>80 \text { yds } \\
\text { (3) }\end{array}$ & $\begin{array}{c}\text { Game Type = } \\
\text { Highly Salient: } \\
\text { (1) \& [(2) or } \\
\text { (3)] } \\
\text { (4) }\end{array}$ \\
\hline \multicolumn{5}{|l|}{$\underline{\text { More Salient Games (Game Type }=1 \text { ) }}$} \\
\hline (a) Loss $\times$ Predicted Win (Upset Loss) & $.126(.034)$ & $.197(.046)$ & $.151(.048)$ & $.172(.045)$ \\
\hline Loss $\times$ Predicted Close (Close Loss) & $.054(.031)$ & $.011(.053)$ & $.027(.038)$ & $.082(.046)$ \\
\hline Win $\times$ Predicted Loss (Upset Win) & $.027(.048)$ & $.156(.080)$ & $.083(.040)$ & $.063(.059)$ \\
\hline Predicted Win & $-.021(.028)$ & $-.042(.036)$ & $-.055(.035)$ & $-.042(.029)$ \\
\hline Predicted Close & $-.040(.034)$ & $-.021(.051)$ & $.019(.038)$ & $-.068(.044)$ \\
\hline Predicted Loss & $-.023(.033)$ & $-.042(.055)$ & $-.024(.026)$ & $.010(.038)$ \\
\hline \multicolumn{5}{|l|}{ Less Salient Games (Game Type $=0$ ) } \\
\hline (b) Loss $\times$ Predicted Win (Upset Loss) & $-.016(.080)$ & $.080(.034)$ & $.070(.037)$ & $.028(.041)$ \\
\hline Loss $\times$ Predicted Close (Close Loss) & $-.003(.030)$ & $.035(.026)$ & $.042(.034)$ & $.018(.028)$ \\
\hline Win $\times$ Predicted Loss $($ Upset Win) & $.002(.039)$ & $-.011(.030)$ & $-.024(.033)$ & $-.004(.027)$ \\
\hline Predicted Win & $-.013(.055)$ & $-.014(.027)$ & $-.009(.028)$ & $-.010(.030)$ \\
\hline Predicted Close & $.032(.032)$ & $-.012(.029)$ & $-.012(.032)$ & $.004(.029)$ \\
\hline Predicted Loss & $-.008(.028)$ & $-.012(.020)$ & $.006(.027)$ & $-.023(.021)$ \\
\hline Non-game Day & --- & --- & --- & --- \\
\hline \multicolumn{5}{|l|}{ Salience Test: } \\
\hline $\mathrm{p}$-value for row $(\mathrm{a})=$ row $(\mathrm{b})$ & .11 & .01 & .17 & .01 \\
\hline Number of Agencies & 764 & 764 & 764 & 764 \\
\hline Observations & 79,386 & 79,386 & 79,386 & 79,386 \\
\hline
\end{tabular}

Notes: Standard errors in parentheses, clustered by team×season. Regressions include agency fixed effects, season dummies, week of season dummies, and the holiday and weather variables described in the note to Table 4. Estimated models are comparable to the baseline model in column 3 of Table 4 . See notes to Table 4 for details. Each column is a single regression which allows for separate coefficients by game type. Still in playoff contention indicates that a team has a greater than $10 \%$ chance of making the playoffs given their current win-loss record, based on the probability that any NFL team made the playoffs with such a win-loss record between 1995 and 2006. Traditional rivals indicates a game between traditional rivals, as defined by "Rivalries in the National Football League" on Wikipedia. 


\section{Table VII}

Updating Based on the Halftime Score Differential.

\begin{tabular}{|c|c|c|c|}
\hline & \multicolumn{3}{|c|}{$\begin{array}{l}\text { Poisson Regression } \\
\text { ate Partner Violence, Male on Female, at Home }\end{array}$} \\
\hline & (1) & (2) & (3) \\
\hline Loss $\times$ Predicted Win (Upset Loss) & $.116(.033)$ & $.105(.028)$ & $.142(.033)$ \\
\hline Loss $\times$ Predicted Close (Close Loss) & $.046(.024)$ & $.035(.020)$ & $.059(.026)$ \\
\hline Win $\times$ Predicted Loss (Upset Win) & $.006(.029)$ & $.007(.025)$ & $-.015(.030)$ \\
\hline Loss $\times$ Halftime Predicted Win (Halftime Upset Loss) & $-.010(.031)$ & & $-.030(.035)$ \\
\hline Loss $\times$ Halftime Predicted Close (Halftime Close Loss) & $-.036(.021)$ & & $-.047(.026)$ \\
\hline Win $\times$ Halftime Predicted Loss (Halftime Upset Win) & $.004(.037)$ & & $.023(.042)$ \\
\hline Predicted Win & $-.018(.026)$ & & \\
\hline Predicted Close & $-.014(.028)$ & & \\
\hline Predicted Loss & $-.006(.022)$ & & \\
\hline Spread & & $.001(.002)$ & $.003(.002)$ \\
\hline Halftime Spread & & & $-.001(.001)$ \\
\hline Non-game Day & & $.016(.019)$ & $.015(.020)$ \\
\hline \multicolumn{4}{|l|}{ Joint Significance of Halftime Variables } \\
\hline p-value & .36 & & .50 \\
\hline Number of Agencies & 764 & 764 & 764 \\
\hline Observations & 79,386 & 79,386 & 79,386 \\
\hline
\end{tabular}

Notes: Standard errors in parentheses, clustered by team $\times$ season. Regressions include agency fixed effects, season dummies, week of season dummies, and the holiday and weather variables described in the note to Table 4.Estimated models are comparable to the baseline model in column 3 of Table 4. See notes to Table 4 for details. Predicted win, predicted close, and predicted loss are based on the pre-game point spread (negative spreads indicate the number of points a team is expected to win by). Predicted win indicates a point spread of -4 or less; predicted close indicates a point spread between -4 and +4 exclusive; predicted loss indicates a spread of +4 or more. Halftime predicted win, halftime predicted close, and halftime predicted loss are based on the halftime "point spread," which is the observed point difference at halftime (where a negative halftime spread indicates the number of points a team is actually winning by at halftime). Predicted halftime win indicates a halftime spread of -4 or less; predicted halftime close indicates a halftime spread between -4 and +4 exclusive; predicted halftime loss indicates a halftime spread of +4 or more. For an analysis of the relative predictive power of these measures, see the online Appendix Table 1. 